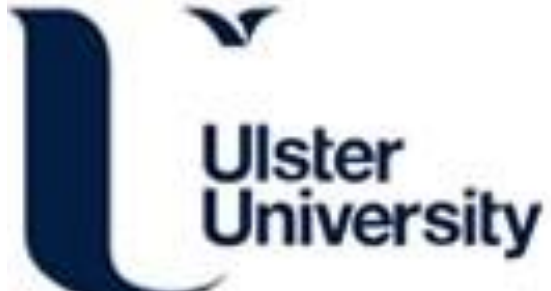

\section{Advancement of a Conceptual Framework for Positional Competition in Sport: Development and Validation of the Positional Competition in Team Sports Questionnaire}

\author{
Harenberg, S., Riemer, H. A., Dorsch, K. D., Karreman, E., \& Paradis, K. F. (2019). Advancement of a \\ Conceptual Framework for Positional Competition in Sport: Development and Validation of the Positional \\ Competition in Team Sports Questionnaire. Journal of Applied Sport Psychology, 33(3), 321-342. \\ https://doi.org/10.1080/10413200.2019.1631903
}

Link to publication record in Ulster University Research Portal

Published in:

Journal of Applied Sport Psychology

Publication Status:

Published (in print/issue): 25/07/2019

DOI:

10.1080/10413200.2019.1631903

\section{Document Version}

Author Accepted version

\section{General rights}

Copyright for the publications made accessible via Ulster University's Research Portal is retained by the author(s) and / or other copyright owners and it is a condition of accessing these publications that users recognise and abide by the legal requirements associated with these rights.

\section{Take down policy}

The Research Portal is Ulster University's institutional repository that provides access to Ulster's research outputs. Every effort has been made to ensure that content in the Research Portal does not infringe any person's rights, or applicable UK laws. If you discover content in the Research Portal that you believe breaches copyright or violates any law, please contact pure-support@ulster.ac.uk. 


\section{Abstract}

2 In high performance team sports, athletes compete with athletes from other teams (e.g., game,

3 event) but also with teammates (e.g., for playing time). The aim of the present study was to: a)

4 present a conceptual framework to further the understanding of positional competition (i.e., the

5 competition for playing time), and b) present the development and validation process of the

6 Positional Competition in Team Sports Questionnaire (PCTSQ). A conceptual framework

7 representing the inputs (e.g., individual characteristics, group processes, coaching decisions),

8 mediators (e.g., information-related processes, performance-related processes, emergent states)

9 and outputs (e.g., individual outputs, team outputs) of positional competition is proposed. The

10 development of the PCTSQ was conducted over four stages (i.e., item generation, preliminary

11 item analysis, scale refinement using CFA and ESEM, estimation of validity and reliability),

12 which included data collected from two samples (i.e., 221 undergraduate Kinesiology students

13 and $812 \mathrm{U}$ Sports/NCAA team sport athletes). The questionnaire was reduced from 127 to 25

14 items, measuring positional competition across seven dimensions. The CFA and ESEM outputs

15 revealed an acceptable fit of the final version of the PCTSQ. In addition, acceptable internal

16 consistency scores for all dimensions of the scale and initial evidence of convergent validity

17 were demonstrated. The PCTSQ is a novel scale to assess positional competition for playing time

18 in team sport, which may aid researchers and practitioners to assess competitive processes within

19 high performance team sports. 
Advancement of a Conceptual Framework and Instrument to Assess Positional Competition in Sport Teams: The Positional Competition in Team Sports Questionnaire Competition, as a social process, has been at the center of research attention in social sciences for over a century (Johnson \& Johnson, 2003), likely due to its omnipresence in day-today life. Individuals encounter competition in organizations (e.g., for promotion), in schools (e.g., for grades), and even during leisure time (e.g., in video games). Additionally, one realm in which competition is frequently experienced is sports (Stanne, Johnson, \& Johnson, 1999). Coakley and Donnelly (2004) argued that competition is an integral part of sports. The organization of sports is competitive, with organized leagues that provide structure and a sequence to competitive events (e.g., a schedule when a team is playing another team, rankings). Competition manifests itself in sport in a variety of ways. Likewise, people will engage in competition in sports for a variety of different reasons, both intrinsic and extrinsic, instrumental and affective. For example, Deutsch (2000) pointed out that friends might engage in a weekly tennis match for the pure enjoyment of the competition. It is the engagement in the mutually pleasurable/profitable activity that is the driving force of participation. In contrast, a professional runner might engage in a competitive run for the sole purpose of winning and the financial rewards associated with it. The reason for the engagement is the excellence in performance in comparison to others. Typically, excellence in sport is often measured through the assessment of one's abilities in comparison to another (Stanne et al., 1999).

In a sports context, Chelladurai (2012) defined these two approaches to competition as the pursuit of pleasure and the pursuit of excellence. The pursuit of pleasure describes activities in which participants engage for participation's sake. In such egalitarian sports, everybody gets the chance to participate regardless of ability level. For example, athletes in a recreational soccer 
1 may participate for the sake of enjoyment of the sport. In this context, the distribution of playing

2 time may be kept somewhat equal between athletes of different ability levels to give everyone

3 the chance to enjoy participation. On the contrary, the pursuit of excellence is characterized by

4 comparison. Individuals engage in the pursuit to win. Chelladurai (2012) calls the pursuit of

5 excellence 'serious business', which is exclusive in nature. That is, only selected athletes who

6 meet the ability requirements at a high-performance level may participate in the pursuit of

7 excellence. For example, on a professional soccer team, winning is an important component of

8 the overall evaluation of the coaches' and players' performances. In such a context, only the best

9 performing players will receive playing time to maximize the odds of winning.

Another important consideration about the pursuit of excellence is that competition does

11 not only take place between teams (i.e., inter-team) but also within a team (i.e., intra-team).

12 Typically, high performance teams (i.e., teams who follow the pursuit of excellence) will have

13 more players on the roster than actual playing positions available. In this case, athletes are

14 required to compete for playing time against their own teammates (Rees \& Segal, 1984; Van

15 Yperen, 1992). Although there is considerable anecdotal evidence for this competition within a

16 team (e.g., Botterill, 2012), until recently the evaluation of this phenomenon in sport teams has

17 been absent from the sport psychology literature.

18 Martens (1979) argued that constructs in the realm of social psychology, such as

19 competition, should be examined in the context in which they occur. Fittingly, Harenberg,

20 Riemer, Karreman, and Dorsch (2016a) conducted a qualitative exploration of competitive

21 processes within university sport teams. The authors interviewed eight full-time Canadian

22 University Sport (U Sports) coaches from various team sports. The findings revealed two types

23 of competitive processes within teams. First, situational competition describes competitive 
1 practice situations that vary in group size (e.g., one vs. ones, three vs. twos), scoring limit (e.g.,

2 first to seven goals), and/or time restrictions (e.g., a predetermined timeframe). These situations

3 occur on a regular basis during practices. Coaches typically structure these competitive situations

4 intentionally for developmental (e.g., tactical) and motivational (e.g., increasing the intensity and

5 enjoyment) reasons. Although there is usually a winner in situational competition, the

6 consequences for losing are minor to none, organizational (e.g., collection of equipment) or

7 physical (e.g., a set of pushups) tasks. As Chelladurai (2012) suspected, the findings indicated

8 that coaches use situational competition for overall improvement of abilities and other positive

9 team outcomes in order to pursue excellence.

Another process described by the coaches was positional competition, the vying for

11 playing time between teammates in a particular position (Harenberg et al., 2016a). There are

12 usually several players per position on the roster of high performance sport teams. Thus, athletes

13 need to compete for a scarce resource (i.e., playing time) against a specific reference group (i.e.,

14 players in the same position). Yet, in contrast to situational competition with a set end point (e.g.,

15 a score limit, expiry of time), positional competition is an ongoing group process between

16 teammates. That is, the competition for playing time does not end at a particular moment (e.g.,

17 end of a game). It is rather a continuous process of comparison that only ends when a) an athlete

18 leaves a team, or b) there is only one athlete for a particular position. Harenberg et al. (2016a)

19 note that positional competition is a process that may have important implications for team

20 functioning, yet it has not yet been examined empirically in the current sport psychology

21 literature.

22 To gain a better conceptual understanding of positional competition, Harenberg, Riemer,

23 Karreman, and Dorsch (2016b) examined athletes' perspectives of positional competition using a 
1 qualitative phenomenological approach. The authors interviewed 16 Canadian University Sport

2 (U Sports) athletes in team sports. The results demonstrated that positional competition is a

3 multi-dimensional (e.g., information- and performance-related facets), ongoing group process

4 that occurs between teammates competing for the same playing time in a particular position. The

5 authors highlighted the adaptive potential of the process but also underline the need for a more

6 structured approach to researching positional competition in a sport context. To carefully study

7 this construct, it first needs to be clearly operationalized and conceptualized (Nunnally \&

8 Bernstein, 1994). Hence, the first purpose of the present study is to advance a definition and

9 conceptual framework of positional competition in team sport, based on the qualitative evidence

10 and relevant literature.

\section{Defining Positional Competition}

The first step to measuring a construct is to define the construct being measured

13 (Tenenbaum, Eklund, \& Kamata, 2012). According to the findings of Harenberg et al.'s (2016a,

14 2016b) studies, positional competition is defined as the process of teammates vying for the same

15 limited playing time in one position. It is a team process that is dynamic (i.e., varies in intensity)

16 and ongoing (i.e., does not have a clear end point), consequently lasts longer than a particular

17 static situation, and involves all agents of sport teams (e.g., the athlete, teammates, coaches).

18 There are four important considerations that accompany the definition of positional competition.

19 First, positional competition only occurs between players in the same position (Rees \& Segal,

20 1984; Van Yperen, 1992). Players in different positions (e.g., a forward and a goalie) do not

21 compete directly for the same limited playing time. Second, high performance athletes desire the

22 most amount of playing time and are encouraged to strive for more playing time. This

23 competition may lead to superior outcomes because it may push individual athletes to perform to 
1 higher standards, thus enhancing collective performance resources (Chelladurai, 2012). Third,

2 positional competition is an ongoing process (Harenberg et al., 2016a, 2016b). There is no

3 definite winner or loser. Rather starting/playing status may fluctuate over time. Also, positional

4 competition begins and ends with the membership on a team, given that there are more players

5 than available playing positions. Once an athlete has joined a team, vying for playing time begins

6 and can last over multiple weeks, months, and seasons, until the athlete leaves the team. Lastly,

7 positional competition always occurs with the awareness of the coach. The (head) coach is a

8 central agent in positional competition because of the associated reward power of the distribution

9 of playing time (Laios, Theodorakis, \& Gargalianos, 2003).

10 Conceptualizing Positional Competition

11 One needs to have a clear conceptual understanding of a phenomenon before one can

12 measure it empirically (Nunnally \& Bernstein, 1994). A theoretical framework provides a good

13 starting point in understanding a complex phenomenon (Tenenbaum et al., 2012). As such, the

14 following section provides a conceptual framework of positional competition that builds largely

15 on the qualitative studies conducted by Harenberg et al. (2016a, 2016b) and relevant literature.

16 The conceptualization of positional competition will follow the Input-Mediator-Output (IMO)

17 framework. As Mathieu et al. (2008) outlined, the IMO framework provides three main

18 advantages in describing group processes compared to other traditional framework (e.g., Input-

19 Process-Outcome, IPO, McGrath, 1964): First, the framework considers that group processes

20 never fully develop as separate entities but are consistently influenced by emergent states. That

21 is, these emergent states can be seen as cognitive, motivational, and affective states that are

22 dynamic and consistently influence inputs, mediators, and outcomes of team functioning (Marks,

23 Matthieu, \& Zaccaro, 2001). An example of a common mediator for an emergent state in sport is 
1 cohesion (e.g., Paradis \& Loughead, 2012), which develops dynamically and affects several

2 constructs related to team functioning (Carron, Colman, Wheeler, \& Stevens, 2002; McEwan \&

3 Beauchamp, 2014; Paradis \& Martin, 2012). Second, the IMO framework views the individual

4 nested within the group. Team members, with their individual characteristics, are influenced by a

5 team's group processes (e.g., leadership, social norms), which are nested in the larger

6 organizational structure of the team (e.g., organizational characteristics). Lastly, the IMO

7 framework captures the dynamics of group processes (i.e., they change over time). That is,

8 groups are entities that consistently fluctuate in their effectiveness and social fabric, due to

9 various internal and external influences (Carron \& Eys, 2012). A larger discussion of the

10 conceptual differences between the IMO and IPO frameworks is provided elsewhere (Mathieu et 11 al., 2008).

12 In a sport context, the IMO model is well suited for the description of group processes.

13 For example, McEwan and Beauchamp (2014) illustrated its applicability to the

14 conceptualization of teamwork. Models using the IMO framework may capture the dynamics of

15 changing processes within sport teams more accurately. Moreover, these processes may progress

16 in episodic cycles (e.g., week-to-week) and may develop over a longitudinal perspective (e.g.,

17 season-to season). Positional competition, much like teamwork, is conceptualized as a dynamic

18 process within teams. It changes over episodic cycles (e.g., from pre-season to mid-season) and

19 may develop longitudinally (e.g., by changing compositions of the team from season to season).

20 Hence, positional competition will be conceptualized using the IMO framework. A model of

21 positional competition is described below and visually displayed in Figure 1.

\section{Inputs of Positional Competition}


Building on Mathieu et al.'s (2008) work, the anticipated sources of inputs of positional competition are threefold: 1) individual inputs, 2) team inputs, and 3) environmental inputs.

Among the individual inputs, a multitude of cognitive, affective, and behavioral factors may influence positional competition. The cognitive appraisal of the competence of other players might play an important role in formulating emotional and behavioral responses to positional competition (Fletcher \& Fletcher, 2005). In addition, the competitiveness of an athlete (e.g., enjoyment and desire to strive for success in competition; Gill \& Deeter, 1988) may influence positional competition. For example, competitive athletes may respond to positional competition with increased motivation and performance (Harenberg et al., 2016b). The expectations and goals set by the athlete (e.g., being a substitute player, desired playing time minutes, being a regular starter) may influence athletes' behavior in positional competition as well.

$$
\text { The individual athletes are nested within teams that have specific team inputs to }
$$

positional competition. These are mainly structural, behavioral, and/or psychological processes within the team. In particular, Carron and Eys (2012) describe several factors (e.g., group size, leadership structure, task interdependence) that may influence group processes. For example, teams may establish certain norms (i.e., standards that regulate group members' behavior; Forsyth, 1999) that influence positional competition. That is, athletes may have established a common set of certain behaviors that are acceptable (e.g., being respectful to competitors) and not acceptable (e.g., trying to injure competitors) in positional competition (Harenberg et al., 2016b). Such team norms may influence how an athlete responds motivationally and behaviorally to positional competition. These responses have been documented in previous literature (Harenberg et al., 2016b; Boroumand, Eys, \& Benson, 2018). Another important factor of the team is the group composition (i.e., the players who are selected for the team, which 
1 comprise the team resources and talents). In a university sport context, the coach selects players

2 to join the team. The individual ability of the recruited players influences positional competition.

3 In addition, the coach assigns a position (i.e., a physical location on the field) and a task role

4 (i.e., set of behaviors associated with the position) to each player (Carron \& Eys, 2012). The

5 overlap in position dictates the group of competitors for playing time (e.g., forward vs. forward).

6 Lastly, the environmental inputs describe factors external to the team that may influence

7 positional competition. For example, organizational structures or sport rules may influence how

8 playing time competition is carried out. In youth organizations, competitors for playing time may

9 be assured a set amount of playing time despite differences in playing ability. In professional or

10 university sport, this might not be the case. In addition, depictions of competition for playing

11 time in the media (e.g., televised discussions of playing time decisions by experts) may influence

12 how players experience positional competition. Lastly, some sports permit unlimited

13 substitutions (e.g., volleyball, basketball, hockey) whereas other sports limit the amount of

14 players to enter the game (e.g., soccer).

15 Mediators - Processes and Emergent States

16 Mediators in the proposed framework are comprised of processes and emergent states,

17 which interact in a team environment. Yet, the distinction between the two is important. In the

18 present conceptualization, positional competition is described as a team process, which manifests

19 in observable behaviors that reflect the nature of team member interaction, which in turn

20 influences group outcomes. Some of these observable behaviors include the setting of individual

21 goals related to playing time and seeking out communication with the coach to understand the

22 hierarchy structure within the team. As such, the processes in the present model reflect

23 information-related and performance-related perceptual processes associated with positional 
1 competition. Emergent states are by-products of team experiences, which are mutually related to

2 inputs, processes, and outputs (Marks et al., 2001; McEwan \& Beauchamp, 2014). For example,

3 conflict may arise as a by-product of the positional competition between established and new

4 team members (Boroumand et al., 2018; Harenberg et al., 2016b), which in turn may influence

5 behaviors and perceptions associated with positional competition. Yet, teams engaging in

6 positional competition may not always experience conflict.

7 Processes. Athletes described two groups of processes of positional competition:

8 information-related (self-evaluation, feedback from teammates, feedback from coaches) and

9 performance-related (teammates pushing each other to get better, and development of own

10 ability) processes (Harenberg et al., 2016b). First, information-related processes reflect the

11 desire of an athlete to gain information on his/her ability and competency relative to teammates

12 in the same position. The three sub-processes for information-related processes can be self-

13 evaluation, feedback from teammates, and feedback from the coach. These three sources of

14 information are central to describing information-related processes in the proposed framework.

15 Individuals tend to seek out self-evaluative information by comparison when objective,

16 nonsocial standards are absent (Festinger, 1954). This is usually the case for the distribution of

17 playing time in interdependent team sports as some performance criteria may not be objectively

18 measurable (e.g., tactical positioning). Thus, athletes will derive information of their ability in

19 comparison to other athletes. In particular, Harenberg et al. (2016b) suggested that self-

20 awareness (i.e., an athlete's perception about his/her capabilities when competing against

21 teammates) and performance expectations (i.e., an athletes' understanding of expected behavior

22 when competing against teammates) are processes of self-evaluation during positional

23 competition. 
Another source for information-related processes is the feedback that an athlete receives

2 from teammates. In particular, athletes tend to praise teammates for good performance aspects or

3 share constructive feedback on how to enhance collective performance (Harenberg et al., 2016b).

4 Through this process, athletes may gain further insights into their ability level in relation to the

5 competitors in their position.

6 The interaction with the coach is another central source for information-related processes

7 in positional competition. In particular, there are three sub-processes in positional competition

8 with regards how to gain information from their coach: evaluation, communication, and selection

9 (Harenberg et al., 2016b). Coaches constantly evaluate their athletes' performances in a

10 quantifiable (e.g., through the use of statistics) or non-quantifiable (e.g., video analysis) way.

11 The information derived from these sources will usually be shared with athletes during

12 individual or team meetings. Another central role of the coach is to provide communication of

13 progress. The athletes derive information on how they have progressed in the competition for

14 playing time from the coach. This information may be reflective of how the athlete has

15 progressed, where the athlete can still make some improvements, and how the athlete's current

16 performance ranks compared to other players in the same position.

17 The other main set of processes of positional competition-Performance-related

18 processes - describes perceptions of performance enhancement in the process of competing for

19 playing time. In particular, Harenberg et al. (2016b) identified two sub-processes. The first sub-

20 process is the perception that teammates push each other to get better. That is, athletes strive to

21 play and by doing so they must constantly perform to a superior degree than their positional

22 competitors. The perception of being pushed and/or being able to push teammates is a key 
1 component of contributing to the overall team's performance and is very much encouraged by

2 coaches (Harenberg et al., 2016a).

3 The second sub-process is the development of one's abilities through forced

4 improvement and learning from competitors. When athletes are competing for playing time, each

5 other's performances are usually the reference point. If an athlete wishes to earn playing time,

$6 \mathrm{he} / \mathrm{she}$ needs to rise to and/or exceed the level of the competition in relation to their teammates in

7 a particular playing position. Performance improvements are necessary to compete for playing

8 time. During this process, athletes closely monitor the progress and strengths of competitors.

9 From this monitoring, athletes may gain valuable insights into their performances and how they

10 may improve further.

11 Emergent States. Two emergent states are included in the model (yet others may exist):

12 cohesion and conflict. Cohesion has been defined as "a dynamic process that is reflected in the

13 tendency of a group to stick together and remain united in pursuit of its instrumental objectives

14 and/or for the satisfaction of member affective needs" (Carron, Brawley, \& Widmeyer, 1998, p.

15 213). Cohesion is manifested in social (i.e., attraction to group/integration in group for

16 interpersonal and affective activities and behaviors) and task (i.e., attraction to group/integration

17 in group for instrumental objectives and behaviors) components. In the organizational literature,

18 Tjosvold, Johnson, and Johnson (2003) suggest that the quality of the relationship between

19 competitors in interdependent settings plays a central role in the constructiveness of competition.

20 Accordingly, cohesion is an integral team process that may be associated with positional

21 competition in sport (Harenberg et al., 2016b). As such, cohesion is integrated as an emergent

22 state influencing the processes of positional competition. 
A second emergent state is intrateam conflict (i.e., "a dynamic process that occurs

2 between interdependent parties as they experience negative emotional reactions to perceived

3 disagreements and interference with the attainment of their goals", Barki \& Hartwick, 2004, p.

4 234). Similar to cohesion, conflict within teams may be experienced through social and task

5 contexts (Paradis, Carron, \& Martin, 2014a, 2014b). An extensive amount of literature has linked

6 competition to intragroup conflict in educational and business settings (Deutsch, 2000; Tjosvold,

7 Johnson, Johnson, \& Sun, 2006). In sport, conflict was reported as an emergent process that may

8 result in or influence competition for playing time in sport teams (Harenberg et al., 2016a,

9 2016b). Consequently, conflict is considered as an emergent state in the model of positional

10 competition.

\section{Outputs of Positional Competition}

12 The anticipated outputs of positional competition are behavioral, affective, and social

13 states within a team. In particular, these states may be visible at an individual and team level.

14 Competition within a team is a process geared towards the performance enhancement of the

15 team. As such, behavioral states may be an increase in performance excellence of individuals

16 (Stanne et al., 1999) and performance coordination efforts between competitors (Harenberg et

17 al., 2016b). From an affective perspective, positional competition may be linked to individuals'

18 adaptive (e.g., heightened confidence, enjoyment) or maladaptive (e.g., frustrations, anxiety)

19 emotions (Harenberg et al., 2016b). On a social level, positional competition may be used to

20 create competence hierarchies within the team (Boroumand et al., 2018). A key concept related

21 to hierarchies is status within the team (Jacob \& Carron, 1998), particularly pertaining starting or

22 non-starting playing status. In general, positional competition may be understood as a necessary,

23 inevitable process that may influence the task effectiveness of the group. Athletes may help each 
1 other, by competing, to make sure the selected player in each position brings the best

2 performance for the team.

It should be noted here that the presented framework conceptualizes positional

4 competition as a dynamic process that changes over episodic cycles. Teams may transition from

5 cycle to cycle (e.g., from game to game; McEwan \& Beauchamp, 2014). Based on the results

6 (e.g., win or loss) and other contextual factors, inputs, mediators, and outputs of positional

7 competition may vary in intensity. Lastly, it should be noted that positional competition develops

8 over the course of a season. For example, in times of hierarchy uncertainty (e.g., preseason)

9 positional competition may be experienced differently than at the end of the season. Much like

10 other team processes (e.g., team effectiveness), positional competition changes over time as the

11 team matures throughout a season and may be influenced by changes to the composition of the

12 team (e.g., addition/removal of players, player injuries, coaching changes; (Matthieu et al., 2008;

13 McEwan \& Beauchamp, 2014).

\section{Measurement Development}

Based on the conceptual framework presented above, the next aim of the present study is

16 to outline the creation of an instrument (i.e., a questionnaire) to measure the identified processes

17 of positional competition: The Positional Competition in Team Sports Questionnaire (PCTSQ).

18 The development of the instrument is described in four phases. The first phase describes the

19 generation of items and procedures to establish face and content validity (i.e., the expert and/or

20 researcher's judgment or ratings that the content of a self-report measure or item captures some

21 or all aspects of the psychological construct of interest; Hagger \& Chatzisarantis, 2009). The

22 second phase describes procedures of item revision and deletion to reduce redundancy. Phases

23 three and four describe procedures to enhance factorial and construct validity, demonstrate 
1 measurement reliability through internal consistency, and assess convergent validity (i.e., the

2 extent to which constructs are related that should theoretically share a relationship; e.g., Paradis,

3 Carron, \& Martin, 2014b).

\section{$4 \quad$ Phase 1 - Item Generation and Content Validity}

The goal of the first stage in the development of the PCTSQ was to generate items that

6 reflect the processes of positional competition. To accomplish this, data on coaches' and

7 athletes' perspectives of positional competition (Harenberg et al., 2016a, 2016b) and the existing

8 literature on competition within sport teams were examined. A preliminary list of 108 items were

9 generated and given to seven experts (female: $n=4)$ to assess the item content relevance (Dunn,

10 Bouffard, \& Rogers, 1999) for positional competition. This group was comprised of four

11 researchers: two full professors, an associate professor, and a $\mathrm{PhD}$ student in the field of sport

12 psychology. All of these members had extensive experience in research and measurement

13 development of psychometrically sound instruments. In addition, one applied sport psychologist

14 (Masters-level trained) was part of the group. The individual was employed full-time to work

15 with high performance athletes in applied consulting. Lastly, two full-time head coaches of

16 university team sports were part of the group of experts. The group was comprised of individuals

17 that had experience in sport psychology and/or coaching ranging from 5 to 21 years.

18 Content Validity. The experts received a paper copy of the initial list of generated items

19 and proposed dimensions. Under each item, experts were invited to provide qualitative feedback

20 and suggestions for rewording via comment boxes. Moreover, experts provided quantitative

21 feedback (e.g., rating of readability, clarity, and applicability of each item on a 7-point Likert

22 scale, ranging from 1-very hard to 7-very easy) on each item. The comments and quantitative

23 scores (i.e., a score $\leq 4$ by any of the experts, which is the midway point of the scale) were 
1 evaluated for the revision of items. Similar procedures have been employed by previous research

2 (e.g., Cheung \& Power, 2012). In general, experts agreed with the created dimension structure

3 and set of items (i.e., only few of the items were rated $\leq 4)$. About $5.5 \%$ of the items $(n=6)$ were

4 slightly revised in content. The experts commented on the comprehensiveness of the created

5 items in reflecting each sub-dimension. For example, for the dimension Improvement, items

6 reflecting more concrete performance parameters (e.g., learning team tactics, improving mental

7 preparation) were added. Other items were reworded. For example, in the dimension Push by

8 Competitors, the initial wording was changed from referring to the comparison group as

9 'competitors' to 'teammates in my position'. The intention for this change was to clarify the

10 comparison group in positional competition. The resulting version of the questionnaire had 127

11 items reflecting 13 facets (listed in Figure 1 under Phase 1 \& 2) of positional competition. The

12 connection between the processes captured in the framework and the dimensions in the

13 questionnaire can be found in Figure 2. A detailed list of all dimensions and items are outlined

14 elsewhere and thus not repeated here (see Harenberg, 2014). Each facet was represented by at

15 least seven items to allow for a reduction of redundant items. All items had the same preface

16 (i.e., "Think about the competition for playing time that you have with your teammates who play

17 in the same position. In this competition...”) and were measured using a seven-point Likert scale

18 with "Strongly Disagree" (1) and "Strongly Agree" (7) as extreme points.

\section{Phase 2 - Preliminary Item Analysis}

After obtaining ethical approval, the set of 127 items was administered to 221

21 undergraduate Kinesiology students (male $n=66$; mean age $=20.77$ years, $S D=2.74$ years;

22 mean year of study $=2.34, S D=1.20$ ) at a Canadian university. The participants were recruited

23 from an undergraduate sport psychology class. The participation was voluntary and the students 
1 did not receive any class credit for completing the questionnaire. Most of the participants had

2 participated $(97.3 \%)$ in competitive sports (e.g., local, high school, provincial level). Following

3 recommendation by DeVellis (2017), data analyses (using SPSS) included a) the examination of

4 distribution of responses, b) item mean and standard deviation, c) inter-item correlation, d) item-

5 to-total correlations, and e) internal consistency (i.e., Cronbach's $\alpha$, composite reliability;

6 Peterson \& Kim, 2013). These procedures were used to assess the variability in responses, the

7 reliability of subscales, and preliminary factorial validity. Furthermore, the dimensions were

8 correlated with each other to gather information regarding dimensional factor structure and

9 parsimony.

Initial analyses suggested some dimensional modifications. Due to high correlations

11 between the dimensions Improvement, Push Self, and Responsibility to Perform (all $r>.90$ )

12 these dimensions were combined and renamed Effort to Improve. Conceptually, these three

13 dimensions reflect effort-related process within an athlete. Furthermore, the dimensions Coach

14 Feedback and Coach Recognition correlated highly $(r>.90)$ and were combined and renamed

15 Coach Communication. Finally, the dimensions Feedback from Peers and Peer Recognition $(r=$

$16.83)$ were combined to Peer Communication.

17 Inter-item correlations and item-to-total correlations were used to limit item redundancy

18 and ensure the item ideally correlated the highest with its proposed dimension, as opposed to

19 another dimension. If individual items correlated highly $(r>.80)$ they were considered

20 redundant, and one was deleted. All item-to-total correlations $<.50$ were considered weak and

21 such items were deleted (Bearden, Netemeyer, \& Teel, 1989). It was the objective to eliminate

22 items that correlated weakly on their intended dimensions. However, it was also the intention to

23 have a sufficient number of items reflecting the specific dimension in its conceptual entirety. The 
1 resulting structure of the questionnaire had nine dimensions (see Figure 2) with 58 items, with

2 each dimension having at least five items. All internal consistency values were satisfactory (i.e.,

3 Cronbach's $\alpha$ and composite reliability >.7; Nunnally \& Bernstein, 1994).

4 Phase 3 - Scale Refinement

5 In the third phase of the questionnaire development, the PCTSQ was administered to its

6 target population (i.e., university-level team sport athletes) and the resulting data were subjected

7 to confirmatory factor analysis (using maximum likelihood estimation). The participants were

8 recruited via their coaches. Once the coach granted permission for the team's participation,

9 athletes were presented with a paper-based questionnaire at a convenient time for the team (e.g.,

10 after practice). While the athletes were advised that participation was voluntary, all invited

11 athletes completed the questionnaire. In total, 812 U Sports or NCAA athletes (female $n=389$;

12 mean age $=20.30, S D=1.97$; mean experience $=2.57$ years, $S D=1.31$ years $)$ from 36 teams

13 participated. The athletes competed in soccer $(n=262,32.3 \%, 12$ teams $)$, football $(n=201$,

$1424.8 \%, 4$ teams), hockey $(n=178,21.9 \%, 8$ teams $)$, volleyball $(n=156,19.2 \%, 11$ teams $)$, or

15 basketball ( $n=15,1.8 \%, 1$ team). The large sample sizes permitted the researchers to draw

16 random subsamples from the entire sample to test and refine the structure of the PCTSQ. This

17 procedure is similar to the development process of other measures in sport psychology (e.g.,

18 Team Sport Performances Processes Questionnaire; Karreman, 2010; Athlete Satisfaction

19 Questionnaire; Riemer \& Chelladurai, 1998). Hedayat and Sinha (1991) argue that two random

20 subsamples can be considered different and distinct if they differ in the vector structure (i.e.,

21 same subjects, order of subjects) and if the same set of units from the population (or large

22 sample) were employed. Therefore, two random samples drawn from a larger sample may be

23 considered different and distinct. 
Prior to analyses, cases with missing data were deleted listwise $(n=73,8.9 \%)$. The remaining 739 cases were examined; item distributions, means, and standard deviations were

3 calculated to ensure sufficient variability. At this point, no further items needed to be deleted.

4 The sample was randomly split in half. The first half of the sample $(n=370)$ was used for the

5 refinement of the factor structure. The second sample $(n=369)$ was used to confirm the resulting

6 factor structure.

The 58 items in nine proposed dimensions were subjected to both Exploratory Structural

8 Equation Modeling (ESEM) and Confirmatory Factor Analysis (CFA) using MPlus and AMOS.

9 These structural equation models were chosen over other statistical techniques (e.g., exploratory

10 factor analysis) because of an existing theoretical structure (as outlined in the framework) of the

11 dimensions of positional competition (Finch, Immekus, \& French, 2016). A key advantage of

12 using ESEM is that items are permitted to cross-load on several factors, whereas CFA forces

13 these cross-loadings to be 0 (Myers, Ntoumanis, Gunnell, Gucciardi, \& Lee, 2018). As such,

14 ESEM is a less restrictive estimation of model fit. However, Marsh and colleagues (2014) note

15 that "in preliminary analyses at the level of individual items, researchers should compare ESEM

16 and CFA measurement models based on the constructs to be considered" (p. 104). As such, CFA

17 was calculated in addition to ESEM. The following goodness-of-fit indices were considered for

18 all structural equation models (i.e., ESEMs, CFAs) in the present study: $\chi^{2} / d f$ ratio (acceptable

19 fit 2-3, good fit < 2; Schermelleh-Engel, Moosbrugger, \& Müller, 2003), Incremental Fit Index

20 (IFI, acceptable fit >.90, good fit >.95; Jaccard \& Wan, 1996), Nonnormed Fit Index (NNFI or

21 Tucker Lewis Index, acceptable fit > .90, good fit > .95; Bentler \& Bonnet, 1980), Comparative

22 Fit Index (CFI, acceptable fit > .90, good fit > .95; Bentler \& Bonnet, 1980), and Root Mean

23 Square Error of Approximation (RMSEA, acceptable fit .05-.08, good fit .00-.05; Schermelleh- 
1 Engel et al. (2003). For a description of the mathematical principles of each indicator, please see

2 Schermelleh-Engel et al. (2003).

Initial results suggested changes were warranted to the scale. First, high correlations $(r>$

$4 \quad$.80) between the dimensions Push by Teammates and Peer Communication suggested collapsing

5 these dimensions into one, together reflecting behavioral and communication processes received

6 from teammates. The same was found for the dimensions Push Teammates and Feedback to

7 Teammates. These were collapsed to one dimension reflecting behavioral and communication

8 processes from an athlete to the teammates.

9 Next, the scale refinements were made based on the following criteria: (a) the factor

10 loadings of the items to its respective dimensions $(>.60$ considered very good; Comery \& Lee,

11 1992), (b) the modification indices (MI > 10; Byrne, 2016), and (c) the assessment of inter-item

12 correlation $(r>.80$; Kline, 1993). The criteria were assessed by considering the output of the

13 ESEM and CFA. Application of these criteria led to an elimination of 33 items, resulting in a

14 questionnaire structure with 25 items, reflecting seven dimensions. Each dimension consisted of

15 three or more items, as suggested by Marsh (2007).

16 The internal consistency of each dimension was then assessed. All dimensions yielded

17 acceptable Cronbach's $\alpha$ values $(\alpha=.69-.90)$ and composite reliability $(.71-.90)$ values.

18 Following recommendations by Smith, McCarthy, and Anderson (2000), the seven revised

19 dimensions were correlated with the nine dimensions from the previous factor structure to

20 examine whether the original factors were sufficiently represented by the revised factors. For the

21 dimensions that were not combined with another dimension a strong correlation to the original

22 structure was found $(r>.90)$. For the dimensions that were combined out of two dimensions,

23 slightly weaker, but nonetheless sufficient, correlations $(r>.80)$ were found. 
Finally, the factor structure was examined with the first subsample using ESEM. The results indicated a satisfactory fit $\left(\chi^{2} / d f=2.67, \mathrm{NNFI}=.90, \mathrm{CFI}=.95, \mathrm{RMSEA}=.065, \mathrm{CI}_{90 \%}=\right.$

$3.057-.073)$. The CFA output demonstrated acceptable goodness of fit indicators $\left(\chi^{2} / d f=2.54\right.$,

$4 \mathrm{IFI}=.92, \mathrm{NNFI}=.90, \mathrm{CFI}=.92, \mathrm{RMSEA}=.065$, Confidence Interval, $\left.\mathrm{CI}_{(90 \%)}=.059-.071\right)$. The

5 results of the steps outlined above indicate that the proposed structure of the PCTSQ reflects the

6 intended content of the prior structure appropriately, is internally consistent, and valid in its

7 factorial structure.

8 Phase 4 - Confirming Validity and Reliability

9 The data of the second subsample $(n=369)$ of CIS/NCAA athletes from high

10 performance team sports were used at this stage of the present study.

11 Reliability. The internal consistency values for the dimensions are provided in Table 1.

12 The Cronbach's $\alpha$ values ranged from .81 to .87 and composite reliability values ranged from .75

13 to .90 . According to Nunnally and Bernstein (1994), a sufficient cutoff for Cronbach's $\alpha$ and

14 composite reliability is .7. Therefore, the results indicate acceptable levels of internal

15 consistency.

16 Correlations between subscales. None of the correlations among the subscales (see

17 Table 1) surpassed a value of $r>.60$. Only four correlations exceeded the value of $r>.50$, with

18 the dimensions Push by Teammates and Push Teammates being the highest $(r=.57)$. The highest

19 explained variance between dimensions is $32.7 \%$. Therefore, uniqueness of each dimension can

20 be assumed.

21 Factorial validity. Before the factorial structure of the scale was examined, intraclass

22 correlation coefficients (ICC) were calculated to check whether the data was nested within

23 teams. Muthén and Satorra (1995) suggest that an ICC above .20 warrants a multi-level approach 
1 to factor analysis. However, none of the ICCs of the items yielded a value above .16. As such,

2 the data were analyzed at the individual level.

To confirm the final structure of the PCTSQ, we conducted exploratory structural

4 equation modelling (ESEM) followed by CFA. For the present study, ESEM was calculated in

5 MPlus 7.2 using a target rotation with the purpose of confirming the established factor structure

6 from Step 3 (Marsh et al., 2014). ESEM revealed a good overall model fit $\left(\chi^{2} / d f=1.91\right.$, NNFI $=$

$\left.7.95, \mathrm{CFI}=.97, \mathrm{RMSEA}=.050, \mathrm{CI}_{90 \%}=.041-.058\right)$. The items loaded well on their intended

8 factors (see Table 2, factor loading $>.50$ ) with the exception of one item (i.e., item $21-$ my

9 coach selects the starting lineup based on prior performance, factor loading $=.48$ ). Cross-

10 loadings were acceptable $(<.24)$. Overall, the results confirmed the hypothesized structure of the

11 PCTSQ.

12 As a follow-up, a CFA with maximum likelihood estimation of the hypothesized factor

13 structure was conducted in AMOS. The factor loadings of the items were satisfactory $(>.58$; see

14 Table 2). The CFA output demonstrated satisfactory goodness of fit indicators of the proposed

15 factor structure $\left(\chi^{2} / d f=2.26, \mathrm{IFI}=.94, \mathrm{NNFI}=.93, \mathrm{CFI}=.94, \mathrm{RMSEA}=.059, \mathrm{CI}_{(90 \%)} .052-\right.$

$16.065)$

17 Convergent Validity. To examine convergent validity, measures of performance and

18 satisfaction were collected. In particular, the subscales Individual Effort and Interplayer

19 Coordination from the Team Sport Performances Processes Questionnaire (Karreman, 2010)

20 were collected. The processes reflect the individual's perspective of own expended effort as well

21 as the coordination of effort with teammates. Moreover, Satisfaction with Training and

22 Instruction by the coach (Athlete Satisfaction Questionnaire; Riemer \& Chelladurai, 1998) was

23 measured. The scales were both administered as part of the questionnaire used in phase 3 . All 
1 scales had acceptable internal consistency (Cronbach's $\alpha>.70)$. As anticipated, the correlations

2 between the measures and the dimensions of positional competition indicated significant positive 3 relationships $(r=.14-.54$, see Table 1$)$.

4

\section{Discussion}

The purpose of the present study was two-fold: a) to advance a conceptual framework of positional competition and b) to develop and validate a measure of positional competition in high performance team sports. The conceptualization of positional competition is based from the current literature on competition within sport teams and the qualitative findings from previous works (Harenberg et al., 2016a, 2016b) and presents a novel framework that may aid in the understanding of the competition within a team. The aim of the questionnaire development phase was to find the most parsimonious and psychometrically sound instrument to measure positional competition in high performance team sports. The resulting scale of 25 items across seven dimensions provides an instrument that is, to our knowledge, the first questionnaire to measure positional competition in a high performance team sport context. It is a relatively short and usable scale for a variety of team sport contexts (e.g., in different high performance team sports). The PCTSQ represents two salient themes: (a) information-related processes, and (b) performance-related processes. The information-related processes are based on the premise that an athlete who engages in positional competition has a need for self-evaluation of his/her own abilities in relation to the other competitors (Festinger, 1954; Tesser, 1988). These processes are reflected in four dimensions (i.e., Comparison, Self-Awareness, Coach Recognition, Selection).

1 Comparison and Self-Awareness are dimensions that describe information gained through internal perceptual processes of the individual. The dimensions Coach Recognition refers to the 
1 information that an athlete gains through the feedback from a coach. The dimension Selection

2 describes the information a player gains through the process of being selected to play by a coach.

3 The performance-related processes are based on the concept that competition within

4 interdependent groups is used constructively to enhance effort by the competitors involved

5 (Chelladurai, 2012; Tjosvold et al., 2003, 2006). This idea was described by athletes and coaches

6 as 'pushing each other to get better' (Harenberg et al., 2016a, 2016b). Consequently, there are

7 two dimensions that reflect this notion (i.e., Pushing Teammates, Push by Teammates). The

8 dimensions Pushing Teammates describes perceptions of an athlete that s/he is encouraging

9 (through physical performance or verbal guidance) other competitors for the same position to

10 elevate their performance. Conversely, Push by Teammates describes the perception that an

11 athlete's competitors for a position encourage him/her (through physical performance or verbal

12 guidance) to perform better. Finally, the dimension Effort to Improve is the perception that the

13 athlete is working to foster his/her abilities while competing for playing positions.

An important conceptual consideration of the scale is that it measures perceptions

15 regarding the involvement of three agents in the process of positional competition: (a) the

16 individual athlete, (b) teammates in a particular position, and (c) the coach. By competing

17 against others, the athlete gains more insight into his/her own capabilities. Teammates provide

18 normative information on how one is to compete. Teammates also guide the athlete on how to

19 develop his/her abilities further. The coach provides positive feedback and determines who will

20 play. The involvement of those three agents is important because they all influence how

21 positional competition is carried out within the team. Generally, all of these agents follow the

22 same collective goals (e.g., being successful as a team) and are interdependent in their

23 collaborative effort to achieve these goals. 
From a technical perspective, an important consideration when constructing the scale was restricting the reduction of each dimension to no less than three items. It is recommended that

3 multiple indicators (i.e., more than two) should be incorporated into the structure of each

4 measured dimension (Bollen, 1989; Marsh, 2007). Yet, factors with three items may yield

5 insufficient internal consistency in measuring psychological variables (e.g., Watson \& Clark,

6 1997). However, for the present scale three dimensions were reduced to three items to prevent

7 redundancy in item wordings. It should be noted that the eliminated items, surprisingly, did not

8 correlate with each other to the extent that a deletion was necessarily required $(r<.80$, Kline,

9 1993). However, in the interest of uniqueness of the items and the brevity of the scale, the items

10 were deleted respectively. Despite Watson and Clark's (1997) concern about the internal

11 consistency of three-item factors, two of the three-item dimensions (i.e., Self-Awareness, Coach

12 Recognition) demonstrated good internal consistency scores $(\alpha \&$ composite reliability $>.80)$.

13 One of the three-item dimensions still demonstrated acceptable internal consistency scores

14 (Selection; $\alpha=.81$, composite reliability $=.75)$. Taken together, these scores provide evidence

15 for sufficient internal consistency. However, future research should evaluate whether these

16 scores can be replicated in other samples.

17 Significant positive correlations between all dimensions of positional competition,

18 perceptions of performance, and satisfaction provided preliminary evidence of convergent

19 validity. Although the range of correlations was quite large $(r=.14-.54)$, we observed higher

20 correlations between dimensions that conceptually should be related. More specifically, when we

21 consider Table 2, we observe that the perception of individual effort is more highly correlated to

22 Effort to Improve than to any other dimension of the PCTSQ. Furthermore, we see that the

23 performance dimension Inter-Player Coordination and the inter-player dimensions in the 
1 PCTSQ (i.e., Push teammates and Push by Teammates) share the highest correlation. Finally, the

2 Satisfaction with Training and Instruction dimension, which describes the satisfaction with the

3 coach's input into the development of the player, correlated highest with the coaching-influence

4 dimensions (i.e., Coach Recognition, Selection) of the PCTSQ. Weaker correlations were found

5 between Effort to Improve and Coach Recognition and Selection. Taken together, these

6 correlations make conceptual sense and provide preliminary evidence of the convergent validity

7 of the PCTSQ. These initial results provide promising evidence for confident utilization of the

8 scale going forward. However, considering that validity testing is an ongoing process (Carron,

9 Widmeyer, \& Brawley, 1985), researchers and psychometricians should continue to further

10 assess the validity of the scale with different samples.

11 To our knowledge, the PCTSQ is the only instrument that measures competition for

12 playing time within sport teams. Other instruments measuring competition in sports focused on

13 competitive anxiety (e.g., CSAI-2, Martens, Burton, \& Vealey, 1990), motivational climate (e.g.,

14 PMCSQ-2, Newton, Duda, \& Yin, 2000), and competitiveness (e.g., SOQ, Gill \& Deeter, 1988).

15 The only scale that takes competition within a team into account is the Peer Motivational

16 Climate in Youth Sport Questionnaire (PeerMCYSQ, Ntoumanis \& Vazou, 2005). In this

17 questionnaire, a dimension named 'intrateam competition' measures the promotion of inter-

18 individual competition by the peer group. It is measured with three items (i.e., On this team,

19 most athletes try to do better than their teammates; On this team, most athletes encourage each

20 other to outplay their teammates; On this team, most athletes look pleased when they do better

21 than their teammates). Although these items are comparable to the dimension 'Comparison' in

22 the PCTSQ, there are conceptual key considerations that differ between the instruments. First,

23 the PeerMYCSQ was conceptualized for youth sport, the PCTSQ was conceptualized for high 
1 performance (e.g., university) sport. Secondly, the PeerMYCSQ conceptualized competition

2 within a team as a facet of ego-oriented motivational climate and did not specify why the athletes

3 were trying to out-compete each other. The PCTSQ is a measurement instrument of a multi-

4 dimensional model of competition for playing time. Lastly, the PeerMYCSQ refers to 'most

5 athletes' and does not specify which athletes are referred to. Building on the assumption that

6 positional competition occurs between players that occupy the same playing position (Rees \&

7 Segal, 1984; Van Yperen, 1992), the PCTSQ examines the competition that occurs between

8 athletes in the same position. For these conceptual differences, we argue for the use of the

9 PCTSQ to measure competition for playing time in high performance team sport.

The PCTSQ was designed for high performance sport teams with a focus on

11 intercollegiate team sports. The qualitative and quantitative phases included athletes from

12 different interdependent sports (i.e., soccer, football, basketball, volleyball, hockey). This might

13 make the scale more suitable for these particular team sports. From an applied perspective,

14 researchers and applied consultants could use the scale to evaluate the perceptions of positional

15 competition within a team. This information could be helpful in working with coaches and

16 athletes to enhance positive performance outcomes associated with positional competition.

17 Anecdotal evidence (see Botterill, 2005) indicates that the structure of positional competition is a

18 vital element of creating high-performance environments. Empirical evidence collected via the

19 PCTSQ might provide deeper insights into such environments.

20 In the sport context, emergent states, such as cohesion, have been considered key

21 influencing processes into the constructiveness of positional competition (Tjosvold et al., 2003;

22 Harenberg et al., 2016b). It is entirely possible that teams who stick together, socially and

23 instrumentally, find ways to mitigate some of the possible negative consequences of positional 
1 competition (e.g., envy). Future research is clearly needed to test this relationship. In addition,

2 the coach plays an integral role in positional competition (Chelldurai, 2012). For example, the

3 group composition, and the way a coach develops a team and encourages and establishes the

4 norms around athletes engaging in positional competition may play a key role in its

5 constructiveness (Harenberg et al., 2016a). Yet, there is an absence of quantitative evidence as,

6 to our knowledge, this strategy is not reflected in any scales examining coaches' leadership style

7 or behavior. As such, the connection between the coaching dimensions in the PCTSQ (i.e., coach

8 recognition, selection) might provide a significant contribution to understand the role of the

9 coach in positional competition.

There are some conceptual limitations of the PCTSQ, which ideally should be addressed

11 by future research. The present scale has been generated for high performance sport teams in

12 which playing time is distributed competitively. The data in the present study was exclusively

13 collected from university teams. This limits the generalizability to other populations (e.g., high

14 performance youth sport, professional sport). Future research needs to examine the usability,

15 validity, and reliability of the PCTSQ in these populations. A second limitation is that this scale

16 was designed primarily for team sports. However, competition could also take place between

17 athletes in individual sports (Evans, Eys, \& Wolf, 2013). The competition within individual

18 sports has different characteristics. For example, in most individual sports, there is a measure

19 (e.g., time) that provides more objectivity to the competition between athletes. Based on the

20 results, the coach makes decisions as to who is going to participate in a specific event. For

21 example, a university track and field coach may select only a few athletes of the team to compete

22 in the upcoming meet. Yet, there are no decisions about to the extent to which an athlete can

23 contribute to an event (e.g., with distribution of playing time, substitutions). Therefore, we can 
1 assume that the competition in individual sport teams might look different than in team sports.

2 This should also be examined by further research. A final main limitation is that this scale

3 explicitly focuses on the competition for playing time within a team. Qualitative studies

4 (Harenberg et al., 2016a, 2016b) demonstrated that there are other competitive processes that

5 might take place within a sport team (e.g., competitive situations). Furthermore, athletes might

6 also compete for formal roles (e.g., captaincy) or recognition beyond the team boundaries (e.g.,

7 rookie of the year). There is a definite need for further exploration of competitive processes

8 within sport teams.

9 In summary, the present paper outlined the advancement of a framework of positional

10 competition and the development of the PCTSQ. The steps taken in the development of the scale

11 revealed initial evidence of content, factorial, and convergent validity as well as sufficient

12 internal consistency reliability. From our perspective, the 25 -item, seven-dimension scale is a

13 unique instrument to measure positional competition in a team sport context that can be used

14 with confidence going forward. It will provide key insights into the nature of positional

15 competition in various environments (e.g., collegiate, professional) within sports. 
2 The authors wish to acknowledge Miranda Kaye for her assistance with the statistical analyses. 


\section{References}

Barki, H. \& Hartwick, J. (2004). Conceptualizing the construct of interpersonal conflict. International Journal of Conflict Management, 15, 216-244. doi: 10.1108.eb022913

Bearden, W. O., Netemeyer, R. G., \& Teel, J. E. (1989). Measurement of consumer susceptibility to interpersonal influence. Journal of Consumer Research, 15(4), 473481. doi: $10.1086 / 209186$

Bentler, P., \& Bonett, D. (1980). Significance tests and goodness of fit in the analysis of covariance structures. Psychological Bulletin, 88, 588-606. doi: $10.1037 / 0033-2909.88 .3 .588$

Bollen, K. A. (1989). Structural equations with latent variables. New York: Wiley.

Botterill, C. (2005). Competitive drive: Embracing positive rivalries. In S. Murphy (Ed.), The sport psych handbook (pp. 37-48). Champaign, IL: Human Kinetics.

Boroumand, S., Eys, M. \& Benson A. J. (2018). How status conflict undermines athletes' willingness to help new teammates. Journal of Applied Sport Psychology, 30, 358-365. doi: $10.1080 / 10413200.2017 .1384939$

Byrne, B. (2016). Structural equation modeling with AMOS. New York, NY: Routledge.

Carron, A. V., Colman, M. M., Wheeler, J., \& Stevens, D. (2002). Cohesion and performance in sport: A meta analysis. Journal of Sport \& Exercise Psychology, 24, 168-188. doi: $10.1123 /$ jsep.24.2.168

Carron, A. \& Eys, M. (2012). Group dynamics in sport. Morgantown, WV: FIT.

Carron, A. V., Widmeyer, W. N., \& Brawley, L. R. (1985). The development of an instrument to assess cohesion in sport teams: The Group Environment Questionnaire. Journal of Sport Psychology, 7(3), 244-266. doi: 10.1123/jsp.7.3.244 
1 Chelladurai, P. (2012). Leadership and manifestations. In S. Murphy (Ed.), The Oxford

2 handbook of sport and performance psychology (pp. 328-341). Oxford, UK: Oxford

$3 \quad$ University Press.

4 Cheung, H. N. \& Power, M. J. (2012). The development of a new multidimensional depression

5 assessment scale: Preliminary results. Clinical Psychology and Psychotherapy, 19, 170-178.

6 doi: $10.1002 /$ cpp. 1782

7 Coakley, J. C. \& Donnelly, P. (2004). Sports in society. Toronto: McGraw Hill.

8 Comery, A. L., \& Lee, H. B. (1992). A first course in factor analysis (2nd ed.).

$9 \quad$ Hillsdale, NJ: Erlbaum.

10 Deutsch, M. (2000). Cooperation and competition. In M. Deutsch \& P. T. Coleman

11 (Eds.), The handbook of conflict resolution (pp. 21-40). San Francisco, CA: Bass.

12 DeVellis, R. F. (2017). Scale development - theory and applications. Los Angeles, CA: Sage.

13 Dunn, G. H., Bouffard, M., \& Rogers, W. T. (1999). Assessing item content-relevance in sport

14 psychology scale construction research: Issues and recommendations. Measurement in

15 Physical Education and Exercise Science, 3, 15-36. doi:10.1207/s15327841mpee0301_2

16 Evans, B., Eys, M., \& Wolf, S. (2013). Exploring the nature of interpersonal influence in elite

17 individual sport teams. Journal of Applied Sport Psychology, 25(4), 448-462.

18 doi: $1080 / 10413200.2012 .752769$

19 Festinger, L. (1954). A theory of social comparison processes. Human Relations, 7, 117-140.

20 Finch, W. H., Immekus, J. C., \& French, B. F. (2016). Applied psychometrics using SPSS and

21 AMOS. Charlotte, NC: Information Age Publishing.

22 Forsyth, D. R. (1999). Group dynamics. Belmont, CA: Brooks/Cole. 
1 Gill, D. L., \& Deeter, T. E. (1988). Development of the sport orientation questionnaire. Research

2 Quarterly for Exercise and Sport, 59(3), 191-202. doi:10.1080/02701367.1988.10605504

3 Hagger, M., \& Chatzisarantis, N. (2009). Assumptions in research in sport and exercise

$4 \quad$ psychology. Psychology of Sport and Exercise, 10(5), 511-519.

5 doi: 10.101615.psysport.2009.01.004

6 Harenberg, S. (2014). As iron sharpens iron: Understanding competitive processes in elite sport

7 teams (Doctoral dissertation, University of Regina, Regina, SK, Canada). Retrieved from

$8 \quad$ http://ourspace.uregina.ca/handle/10294/5583.

9 Harenberg, S., Riemer, H., Karreman, E., \& Dorsch, K. (2016a). Competitive processes in elite

10 sport teams: An exploration of coaches' perspectives of intrateam competition. International

11 Sport Coaching Journal, 3(2), 156-169. doi: 10.1123/iscj.2016-0056

12 Harenberg, S., Riemer, H., Karreman, E., \& Dorsch, K. (2016b). As iron sharpens iron? Athletes'

13 perspectives of positional competition. The Sport Psychologist, 30(1), 55-67.

14 doi: $10.1123 /$ tsp.2014-0131

15 Hedayat, A. S., \& Sinha, B. K. (1991). Design and inference in finite population sampling. New

16 York, NY: Wiley.

17 Jaccard, J. \& Wan, C. (1996) Lisrel approaches to interaction effects in multiple regression.

18 Thousand Oaks, CA: Sage.

19 Johnson, D. W., \& Johnson, R. T. (2003). Joining together: Group theory and group skills.

20 Boston, MA: Allyn \& Bacon.

21 Johnson, D. W., \& Johnson, R. T. (2005). New developments in social interdependence theory.

22 Genetic, Social, and General Psychology Monographs, 131, 285-358. 
1 Jacob, C. S., \& Carron, A. V. (1998). The association between status and cohesion in sport 2 teams. Journal of Sport Sciences, 16, 187-198.

3 Karreman, E. (2010). Social psychology of athletic teams: Understanding the relationships

4 between cohesion, leadership, satisfaction, and team performance. Unpublished Dissertation,

5 University of Regina, Faculty of Kinesiology and Health Studies, Regina, SK, Canada.

6 Kline, P. (1993). The handbook of psychological testing. London: Routledge.

7 Laios, A., Theodorakis, N., \& Gargalianos, D. (2003). Leadership and power: Two important

8 factors for effective coaching. International Sports Journal, 7(1), 150-154Marks, M. A.,

9 Matthieu, J. E., \& Zaccaro, S. J. (2001). A temporally based framework and taxonomy of

10 team processes. The Academy of Management Review, 26, 356-376.

11 doi: $10.2307 / 259182$

12 Marsh, H. W. (2007). Application of confirmatory factor analysis and structural equation

13 modeling in sport and exercise psychology. In G. Tenenbaum \& R. Eklund (Eds.), Handbook

14 of sport psychology. New York: John Wiley.

15 Marsh, H. W., Morin, A. J. S., Parker, P. D., \& Kaur, G. (2014). Exploratory structural equation 16 modeling: An integration of the best features of exploratory and confirmatory factor analysis.

17 Annual Review of Clinical Psychology, 10, 85-110.

18 doi: 10.1146/annurev-clinpsy-032813-153700

19 Martens, R. (1979). About smocks and jocks. Journal of Sport Psychology, 1, 94-99.

20 Martens, R., Vealey, R. S., \& Burton, D. (1990). Competitive anxiety in sport. Champaign, IL:

21 Human Kinetics. 
1 Mathieu, J. M., Maynard, T., Rapp, T., \& Gilson, L. (2008). Team effectiveness 1997-2007: A

2 review of recent advancements and a glimpse into the future. Journal of Management, 34, 3 410-476. doi: 10.1177/0149206308316061

4 McEwan, D. \& Beauchamp, M. R. (2014). Teamwork in sport: A theoretical and integrative 5 review. International Review of Sport and Exercise Psychology, 7, 229-250.

6 doi: $10.1080 / 1750984 X .2014 .932423$

7 McGrath, J. E. (1964). Social psychology. New York, NY: Holt, Rinehart, \& Winston.

8 Muthén, B. O. \& Satorra, A. (1995). Complex sample data in structural equation modeling.

9 Sociological Methodology, 25, 267-316. doi: 10.2307/271070

10 Myers, N. D., Ntoumanis, N., Gunnell, K. E., Gucciardi, D. F., \& Lee, S. (2018). A review of

11 some emergent quantitative analyses in sport and exercise psychology. International Review

12 of Sport and Exercise Psychology, 11(1), 70-100. doi: 10.1080/1750984X.2017.1317356

13 Newton, M., Duda, J. L., \& Yin, Z. (2000). Examination of the psychometric properties of the

14 Perceived Motivational Climate in Sport Questionnaire-2 in a sample of female athletes.

15 Journal of Sports Sciences, 18(4), 275-290. doi: 10.1080/026404100365018

16 Ntoumanis, N. \& Vazou, S. (2005). Peer motivational climate in youth sport: Measurement

17 development and validation. Journal of Sport \& Exercise Psychology, 27(4), 432-455.

18 doi: 10.1123 jsep.27.4.432

19 Nunnally, J. C., \& Bernstein, I. H. (1994). Psychometric theory. New York, NY: McGraw-Hill.

20 Paradis, K. F., Carron, A. V., \& Martin, L. J. (2014a). Athlete perceptions of intragroup conflict 21 in sport teams. Sport and Exercise Psychology Review, 10(3), 4-18. 
1 Paradis, K. F., Carron, A. V., \& Martin, L. J. (2014b). Development and validation of an

2 inventory to assess conflict in sport teams: The Group Conflict Questionnaire. Journal of

$3 \quad$ Sports Sciences, 32(20), 1966-1978. doi:10.1080/02640414.2014.970220

4 Paradis, K. F., \& Loughead, T. M. (2012). Examining the mediating role of cohesion between

5 athlete leadership and athlete satisfaction in youth sport. International Journal of

6 Sport Psychology, 43, 117-136.

7 Paradis, K. F., \& Martin, L. J. (2012). Team building in sport: Linking theory and research to

8 practical application. Journal of Sport Psychology in Action, 3(3), 159-170.

9 doi:10.1080/21520704.2011.653047

10 Peterson, R. A. \& Kim, Y. (2012). On the relationship between coefficient alpha and composite 11 reliability. Journal of Applied Psychology, 98(1), 194-198. doi: 10.1037/a0030767

12 Rees, C. R. \& Segal, M. W. (1984). Intragroup competition, equity, and interpersonal attraction.

13 Social Psychology Quarterly, 47(4), 328-336. doi: 10.2307/3033635

14 Riemer, H. A., \& Chelladurai, P. (1998). Development of the Athlete Satisfaction Questionnaire 15 (ASQ). Journal of Sport \& Exercise Psychology, 20(2), 127-156. doi: 10.1123/jsep.20.2.127

16 Schermelleh-Engel, K., Moosbrugger, H., \& Müller, H. (2003). Evaluating the fit of structural

17 equation models: Tests of significance and descriptive goodness-of-fit measures. Methods of 18 Psychological Research Online, 8(2), 23-74.

19 Smith, G. T., McCarthy, D. M., \& Anderson, K. G. (2000). On the sins of short-form

20 development. Psychological Assessment, 12(1), 102-111. doi: 10.1037/1040-3590.12.1.102

21 Stanne, M., Johnson, D. \& Johnson, R. (1999). Does competition enhance or inhibit motor

22 performance: A meta-analysis. Psychological Bulletin, 125(1), 133-154.

23 doi: $10.1037 / 0033-2909.125 .1 .133$ 
1 Tenenbaum, G., Eklund, R. C., \& Kamata, A. (2012). Measurement in sport and exercise

2 psychology. Champaign, IL: Human Kinetics.

3 Tesser, A. (1988). Toward a self-evaluation maintenance model of social behavior. Advances in

4 Experimental Social Psychology, 21(1), 181-227. doi:10.1016/S0065-2601(08)60227-0

5 Tjosvold, D., \& Johnson, D. W., Johnson, R. T. (2003). Can interpersonal competition be

6 constructive within organizations? The Journal of Psychology, 137(1), 63-84.

7 doi: $10.1080 / 00223980309600600$

8 Tjosvold, D., Johnson, D. W., Johnson, R. T., \& Sun, H. (2006). Competitive motives and

9 strategies: Understanding constructive competition. Group Dynamics: Theory, Research, and

10 Practice, $10(2), 87-99$. doi: 10.1037/1089-2699.10.2.87

11 Van Yperen, N. (1992). Self-Enhancement among major league soccer players: The role of

12 importance and ambiguity on Social Comparison Behavior. Journal of Applied Social

13 Psychology, 22(15), 1186-1198. doi:10.1111/j.1559-1816.1992.tb02359.x

14 Watson, D. \& Clark, L. (1997). Measurement and mismeasurement of mood: Recurrent and 15 emergent issues. Journal of Personality Assessment, 68(2), 267-29.

16 doi: $10.1207 / \mathrm{s} 15327752$ jpa6802_4 
1

3

4

Table 1

Dimension Internal Consistency, Means, Standard Deviations, and Bivariate Correlations

\begin{tabular}{|c|c|c|c|c|c|c|c|c|c|c|c|}
\hline Dimension & $\alpha / \mathrm{CR}$ & 1. & 2. & 3. & 4. & 5. & 6. & 7. & 8. & 9. & 10. \\
\hline 1. PC - Effort to Improve & $.87 / .86$ & $\begin{array}{l}6.08 \\
(.75)\end{array}$ & & & & & & & & & \\
\hline 2. PC - Push by Teammates & $.88 / .86$ & $.57^{* *}$ & $\begin{array}{l}5.33 \\
(.99)\end{array}$ & & & & & & & & \\
\hline 3. PC - Push Teammates & $.86 / .83$ & $.52^{* *}$ & $.55^{* *}$ & $\begin{array}{l}5.40 \\
(.97)\end{array}$ & & & & & & & \\
\hline 4. PC - Comparison & $.86 / .88$ & $.56^{* *}$ & $.31^{* *}$ & $.43^{* *}$ & $\begin{array}{l}6.01 \\
(.97)\end{array}$ & & & & & & \\
\hline 5. PC - Social Awareness & $.86 / .82$ & $.47^{* *}$ & $.32^{* *}$ & $.47^{* *}$ & $.44^{* *}$ & $\begin{array}{l}5.54 \\
(.92)\end{array}$ & & & & & \\
\hline 6. PC - Coach Recognition & $.84 / .90$ & $.47^{* *}$ & $.43^{* *}$ & $.34^{* *}$ & $.12^{* *}$ & $.32^{* *}$ & $\begin{array}{c}5.25 \\
(1.21)\end{array}$ & & & & \\
\hline 7. PC - Selection & $.81 / .75$ & $.37^{* *}$ & $.33^{* *}$ & $.24^{* *}$ & $.13^{* *}$ & $.26^{* *}$ & $.56^{* *}$ & $\begin{array}{l}5.30 \\
(1.25)\end{array}$ & & & \\
\hline 8. PF - Individual Effort & $.81 / .82$ & $.47^{* *}$ & $.25^{* *}$ & $.27^{* *}$ & $.38^{* *}$ & $.28^{* *}$ & $.21^{* *}$ & $.21^{* *}$ & $\begin{array}{l}6.18 \\
(.76)\end{array}$ & & \\
\hline 9. PF - Interplayer Coordination & $.72 / .73$ & $.46^{* *}$ & $.52^{* *}$ & $.54^{* *}$ & $.27^{* *}$ & $.29^{* *}$ & $.36^{* *}$ & $.24^{* *}$ & $.40^{* *}$ & $\begin{array}{l}5.60 \\
(.70)\end{array}$ & \\
\hline 10. AS - Training and Instruction & $.88 / .88$ & $.36^{* *}$ & $.31^{* *}$ & $.14^{* *}$ & $.14^{* *}$ & $.22^{* *}$ & $.59^{* *}$ & $.44^{* *}$ & $.22^{* *}$ & $.32^{* *}$ & $\begin{array}{c}5.09 \\
(1.37) \\
\end{array}$ \\
\hline
\end{tabular}


Table 2

Item Descriptives and Factor Loadings

\begin{tabular}{|c|c|c|c|c|c|c|c|c|c|c|}
\hline $\begin{array}{l}\text { Sub- } \\
\text { scale }\end{array}$ & Item & $\begin{array}{c}\text { M } \\
(S D) \\
\end{array}$ & CFA & 1. & 2. & 3. & 4. & 5. & 6. & 7. \\
\hline \multirow[t]{4}{*}{$\begin{array}{l}1 . \\
\text { EI }\end{array}$} & $\begin{array}{l}1 \text { I am getting better at fulfilling my } \\
\text { responsibilities as a player in my position. }\end{array}$ & $\begin{array}{l}5.92 \\
(.93)\end{array}$ & .72 & .52 & .09 & .12 & .08 & .01 & .01 & .09 \\
\hline & 8 I challenge myself to be a better player. & $\begin{array}{l}6.32 \\
(.90)\end{array}$ & .78 & .71 & .01 & .11 & .13 & -.09 & .04 & -.11 \\
\hline & $\begin{array}{l}15 \text { I am pushing myself to improve the skills } \\
\text { required in my position }\end{array}$ & $\begin{array}{l}6.19 \\
(.90)\end{array}$ & .81 & .82 & .02 & -.10 & -.04 & .12 & -.04 & .15 \\
\hline & $\begin{array}{l}22 \text { I am pushing myself to improve upon my } \\
\text { weaknesses as a player. }\end{array}$ & $\begin{array}{l}6.22 \\
(.86)\end{array}$ & .79 & .71 & .01 & -.02 & .03 & .04 & .14 & -.10 \\
\hline \multirow[t]{4}{*}{$\begin{array}{l}2 . \\
\text { PbT }\end{array}$} & $\begin{array}{l}2 \text { my teammates in my position push me to } \\
\text { work hard every day. }\end{array}$ & $\begin{array}{c}5.58 \\
(1.19)\end{array}$ & .77 & .22 & .72 & -.04 & -.01 & -.07 & -.08 & .09 \\
\hline & $\begin{array}{l}9 \text { my teammates in my position encourage } \\
\text { me when I am making progress as a player. }\end{array}$ & $\begin{array}{c}5.49 \\
(1.14)\end{array}$ & .76 & -.10 & .90 & .00 & .12 & .02 & -.01 & -.02 \\
\hline & $\begin{array}{l}16 \text { my teammates in my position point out } \\
\text { aspects I am doing well in our position }\end{array}$ & $\begin{array}{c}5.38 \\
(1.25)\end{array}$ & .76 & .07 & .59 & .12 & -.06 & .10 & .07 & -.04 \\
\hline & $\begin{array}{l}23 \text { my teammates in my position push me to } \\
\text { work on my weaknesses as a player. }\end{array}$ & $\begin{array}{c}5.32 \\
(1.21)\end{array}$ & .82 & -.05 & .65 & .09 & -.04 & .13 & .17 & .00 \\
\hline \multirow[t]{4}{*}{$\begin{array}{l}3 . \\
\text { PT }\end{array}$} & $\begin{array}{l}3 \text { I provide guidance for my teammates in } \\
\text { my position. }\end{array}$ & $\begin{array}{c}5.36 \\
(1.22)\end{array}$ & .69 & -.01 & -.19 & .79 & .02 & .07 & .06 & .03 \\
\hline & $\begin{array}{l}10 \text { I am pushing my teammates in my } \\
\text { position to reach beyond their expected } \\
\text { performance level. }\end{array}$ & $\begin{array}{c}5.36 \\
(1.11)\end{array}$ & .76 & .14 & .02 & .63 & .03 & .01 & .02 & .02 \\
\hline & $\begin{array}{l}17 \text { I am pushing my teammates in my } \\
\text { position to work on their weaknesses as } \\
\text { players. }\end{array}$ & $\begin{array}{c}5.30 \\
(1.20)\end{array}$ & .78 & .06 & .25 & .56 & -.01 & .01 & -.04 & .05 \\
\hline & $\begin{array}{l}24 \text { I talk to my teammates how they can do } \\
\text { better in our position. }\end{array}$ & $\begin{array}{c}5.18 \\
(1.31)\end{array}$ & .76 & -.11 & .11 & .77 & .02 & .04 & -.05 & .00 \\
\hline \multirow[t]{4}{*}{$\begin{array}{l}4 . \\
\text { COM }\end{array}$} & $\begin{array}{l}4 \text { I am constantly trying to be ahead of my } \\
\text { teammates in my position. }\end{array}$ & $\begin{array}{c}6.11 \\
(1.17)\end{array}$ & .71 & .08 & -.09 & .17 & .67 & -.09 & .05 & -.05 \\
\hline & $\begin{array}{l}11 \text { I try to outperform my teammates in my } \\
\text { position. }\end{array}$ & $\begin{array}{c}6.09 \\
(1.13)\end{array}$ & .82 & .00 & -.05 & .04 & .82 & -.01 & .02 & .03 \\
\hline & $\begin{array}{l}18 \text { I strive to show that I am better than my } \\
\text { teammates in my position. }\end{array}$ & $\begin{array}{c}5.79 \\
(1.26)\end{array}$ & .85 & -.09 & .03 & -.07 & .86 & .10 & -.01 & -.03 \\
\hline & $\begin{array}{l}25 \text { I try hard to perform better than my } \\
\text { teammates in my position. }\end{array}$ & $\begin{array}{c}6.04 \\
(1.13)\end{array}$ & .86 & .09 & .04 & -.09 & .82 & .05 & -.05 & .06 \\
\hline \multirow[t]{3}{*}{$\begin{array}{l}5 . \\
\text { SA }\end{array}$} & $\begin{array}{l}5 \text { I know how well I perform compared to } \\
\text { my teammates in my position }\end{array}$ & $\begin{array}{c}5.33 \\
(1.12)\end{array}$ & .77 & .00 & -.03 & .02 & .01 & .80 & -.03 & -.02 \\
\hline & $\begin{array}{l}12 \text { I know what } I \text { am capable of in relation } \\
\text { to my teammates in my position. }\end{array}$ & $\begin{array}{c}5.79 \\
(1.02)\end{array}$ & .81 & .18 & .06 & .15 & -.01 & .62 & -.08 & -.02 \\
\hline & $\begin{array}{l}19 \text { I know where my performance ranks in } \\
\text { comparison to my teammates in my } \\
\text { position. }\end{array}$ & $\begin{array}{c}5.57 \\
(1.18)\end{array}$ & .75 & -.07 & -.02 & -.06 & .07 & .80 & .09 & .03 \\
\hline \multirow[t]{3}{*}{ CR. } & $\begin{array}{l}6 \text { my coach acknowledges when I am } \\
\text { performing well in my position. }\end{array}$ & $\begin{array}{l}5.25 \\
(1.34)\end{array}$ & .86 & .00 & .01 & .06 & -.02 & .05 & .85 & -.01 \\
\hline & $\begin{array}{l}13 \text { my coach acknowledges when I compete } \\
\text { hard as a player. }\end{array}$ & $\begin{array}{c}5.46 \\
(1.36)\end{array}$ & .87 & .07 & .07 & -.08 & -.01 & .01 & .81 & .03 \\
\hline & $\begin{array}{l}20 \text { my coach compliments me on good plays } \\
\text { that I make in my position. }\end{array}$ & $\begin{array}{c}5.33 \\
(1.40)\end{array}$ & .89 & .03 & .01 & .01 & .03 & -.04 & .84 & .08 \\
\hline \multirow[t]{3}{*}{$\begin{array}{l}7 . \\
\text { CS }\end{array}$} & $\begin{array}{l}7 \text { my coach does not select the athletes to } \\
\text { play that perform the most consistent. }\end{array}$ & $\begin{array}{c}5.26 \\
(1.58)\end{array}$ & .67 & .00 & -.07 & .07 & .00 & -.07 & .00 & .72 \\
\hline & $\begin{array}{l}14 \text { the best performing players get playing } \\
\text { time. }\end{array}$ & $\begin{array}{c}5.41 \\
(1.38)\end{array}$ & .85 & .00 & .04 & -.01 & .00 & .05 & .01 & .81 \\
\hline & $\begin{array}{l}21 \text { my coach selects the starting lineup } \\
\text { based on prior performance. }\end{array}$ & $\begin{array}{c}5.27 \\
(1.46)\end{array}$ & .58 & -.01 & .05 & .02 & .03 & .02 & .13 & .48 \\
\hline
\end{tabular}

Note: EI - Effort to Improve, PbT - Push by Teammates, PT - Push Teammates, COM - Communication, SA - Self-Awareness, CR - Coach Recognition, CS - Coach Selection, CFA = Factor Loadings from CFA, 1. - 7. = Factor Loadings from ESEM 
Figure 1

A Conceptual Framework of Positional Competition

INPUTS

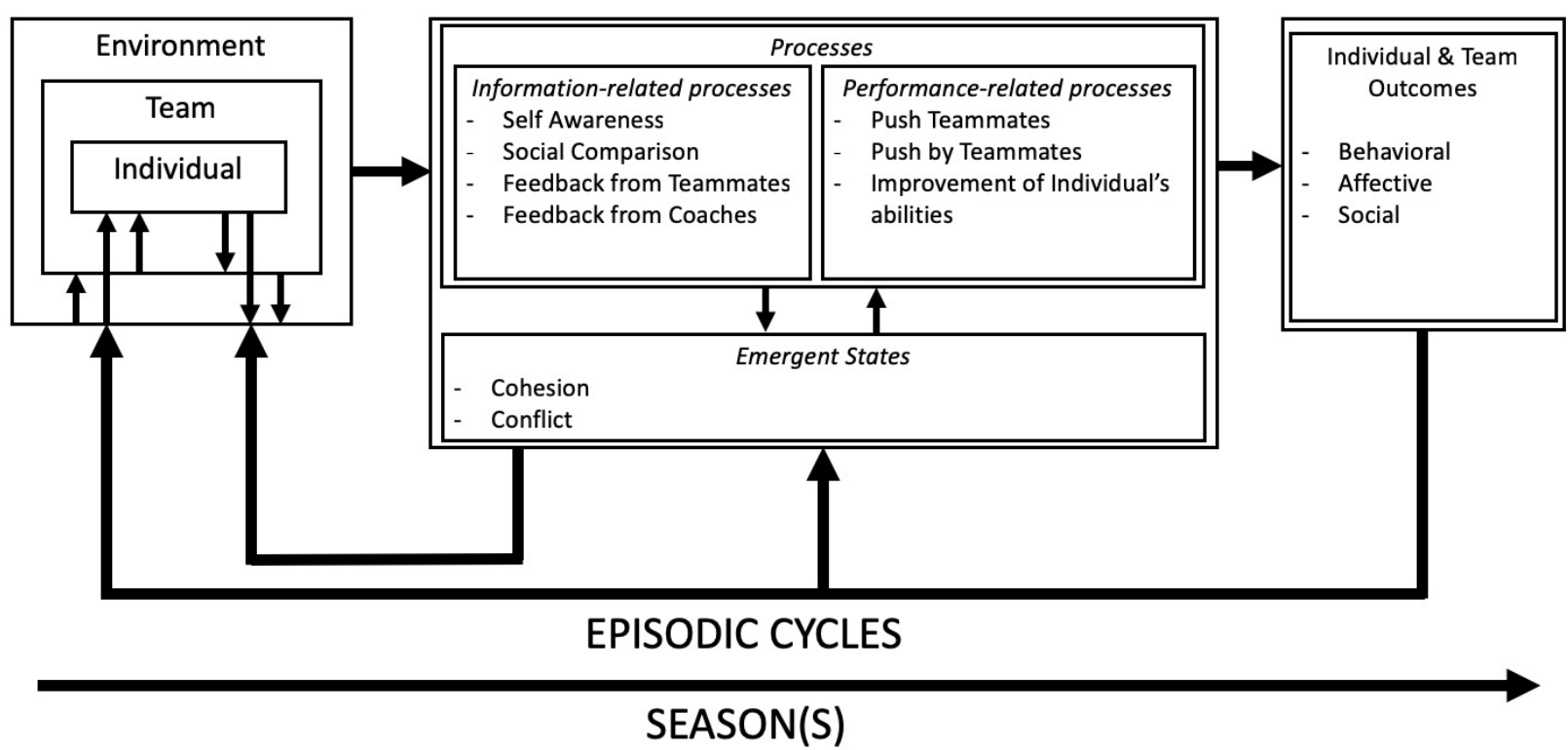

MEDIATORS

OUTPUTS

dividual \& Team

Outcomes

Affective

Improvement of Individual's

SEASON(S) 
Figure 2

Steps of Dimension Reduction

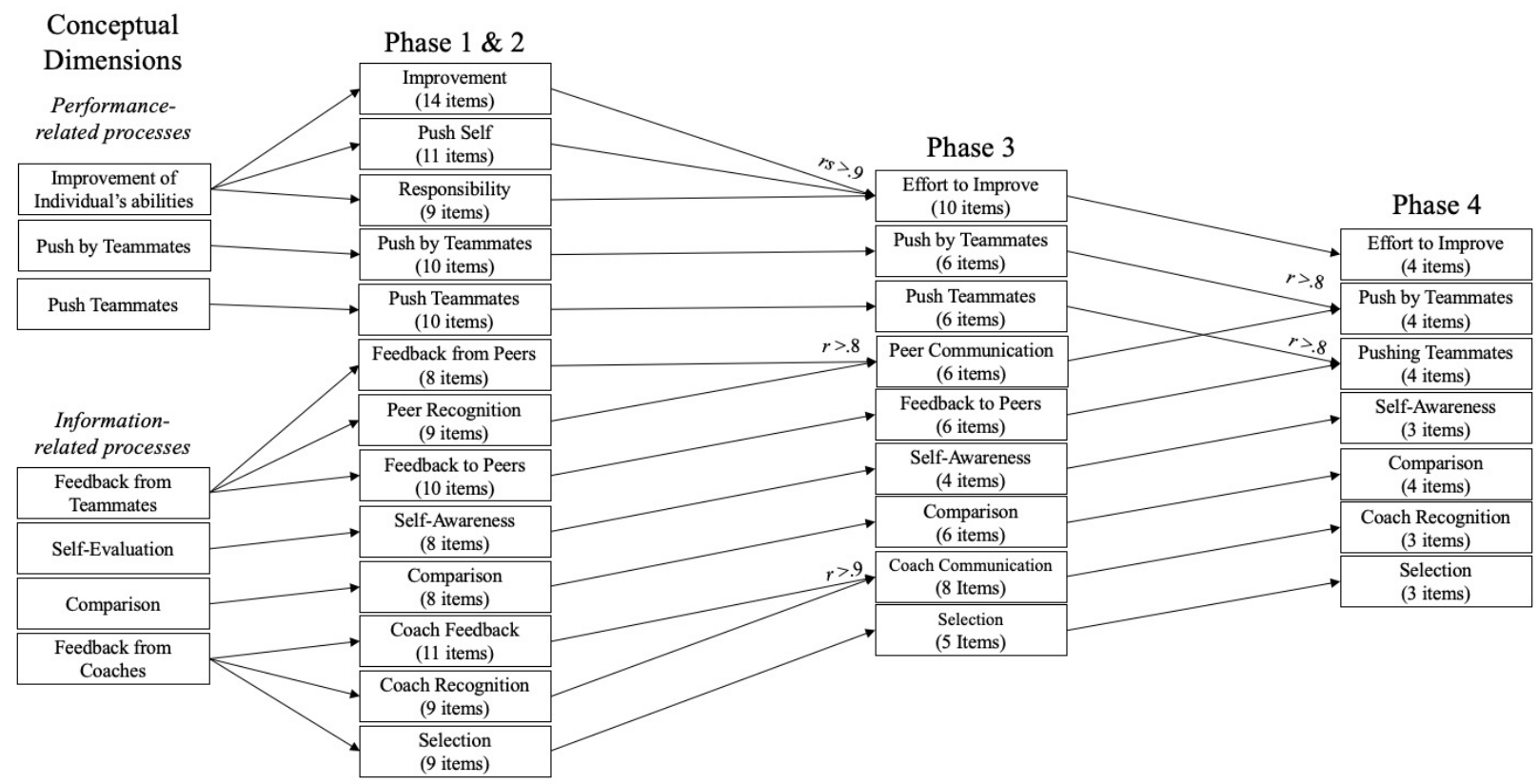

